\title{
Research on the Industrial Economic Development Driving by Scientific and Technological Service System Innovation
}

\author{
Lan Zhang ${ }^{1, \mathrm{a}}$, Xinhui Hao ${ }^{1, \mathrm{~b}}$, Yuhua Zhang ${ }^{1, \mathrm{c}}$, Yonggeng Wang ${ }^{1, \mathrm{~d}}$ \\ ${ }^{1}$ School of Accounting, Jilin University of Finance and Economics, Changchun, China
}

\begin{abstract}
In terms of the mechanism of scientific and technological service promoting innovation and entrepreneurship, innovation can significantly improve labor productivity and labor factor efficiency, and promote the optimization and upgrading of industrial structure. Sustainable economic development must rely on technological innovation. This paper designs an innovative science and technology service system to achieve the goal of industrial economic development from five aspects: market-oriented mechanism, demandoriented mechanism, industry university research collaborative innovation mechanism, scientific and technological financial system construction, and scientific and technological talent team construction.
\end{abstract}

\section{Introduction}

'Made in China 2025' marks the completion of the toplevel design of enterprise innovation at the national level, which highlights the innovation driven development strategy and takes innovation as the core competitiveness of enterprise development. However, with the acceleration of industrial convergence, the environment faced by enterprise innovation will be more complex, and it becomes increasingly difficult to implement effective innovation only by enterprises themselves. Therefore, since the implementation of the innovation driven development strategy, the state has recognized the importance of science and technology services, and has issued supporting policies to guide the transformation and upgrading of traditional industries and promote the industrialization of scientific and technological achievements.

The arrangement of system determines the economic efficiency, and different institutional arrangements will bring different economic efficiency. How to strengthen the scientific and technological services in the development of characteristic industries from the perspective of institutional arrangements is worth studying. At present, the overall efficiency of the innovation system is not high, and many industries are still in the middle and low end of the value chain. The essence of innovation system is "fragmentation" and "isolation" of science and technology and resources, dual track operation of science and technology and economy, and disconnection of innovation chain from industrial chain and capital chain. The main performance is as follows:

- The market-oriented mechanism of scientific and technological innovation is insufficient, the mechanism of scientific research project approval and evaluation mechanism of universities and scientific research institutions deviates from the law of scientific and technological development, and the lack of mechanism and economic environment to promote enterprises to play the role of innovation subject.

- The supporting measures of science and technology entrepreneurship lag behind the actual needs, and the intermediary services such as capital and incubation are not perfect.

- The evaluation and pricing mechanism of scientific and technological achievements is not perfect, and the professional technology transfer service is lacking.

- The financial system in the industrial era is difficult to meet the capital needs of technological enterprises, and the proportion of indirect financing is too large, resulting in the mismatch of financial resources.

Therefore, it is necessary to deepen the reform of system and mechanism, establish and improve the service system of scientific and technological innovation to give full play to the leading role of innovation in development and the support of modern economic system.

\section{Establishing an innovative scientific and technological service system suitable for the industrial economic development}

It is found that the positive interaction mechanism between the development level of science and technology service industry and economic growth has initially formed. In the short term, we should pay attention to the cultivation and support role of the economic development environment for the science and technology service 
industry, and in the medium and long term, we should focus on the promotion and coordination of the scientific and technological service industry on economic growth. The influence mechanism of science and technology service industry to promote economic growth is not only the direct contribution to economic growth, but also the indirect contribution through the circuitous effect of influencing factors on economic growth. In terms of the mechanism of science and technology services promoting innovation and entrepreneurship, innovation can significantly improve labor productivity and labor factor efficiency, and promote the optimization and upgrading of industrial structure. In order to achieve sustainable economic development, we must rely on technological innovation. This paper designs an innovative science and technology service system to achieve the goal of Jilin's comprehensive revitalization from five aspects: marketoriented mechanism, demand-oriented mechanism, industry university research collaborative innovation mechanism, scientific and technological financial system construction, and scientific and technological talent team construction. The details are shown in Figure 1:

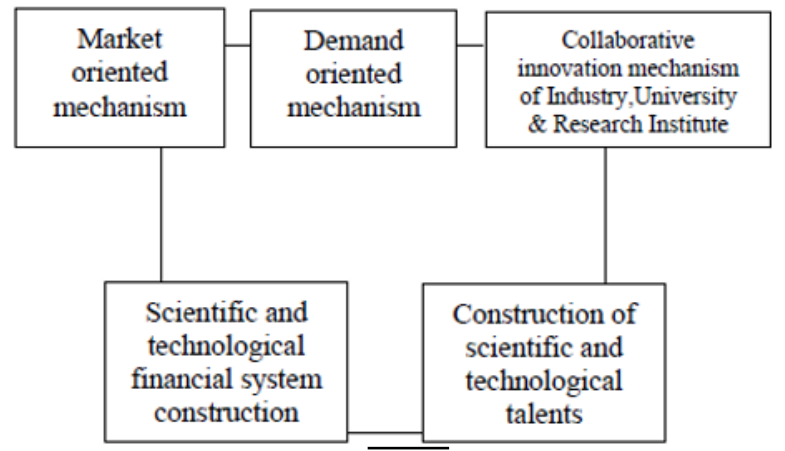

Fig1. Frame chart of the Industrial Economic Development Driving by Scientific and Technological Service System Innovation

\subsection{Establish a market-oriented mechanism for science and technology services and improve the allocation and utilization efficiency of science and technology resources}

A perfect market system is an important guarantee for economic development. The perfect market system can make production, exchange, distribution and consumption orderly, reduce the resistance of economic development, and make the economic blood flow rapidly. In the aspect of science and technology system reform, we should improve the market-oriented mechanism of technological innovation and give full play to the guiding role of the market in the direction of technological research and development, route selection, factor price and allocation of various innovative elements. It not only promotes the reform of science and technology system, but also provides impetus for the realization of innovation driven development strategy.

First, according to different stages of development, we should adopt various ways to support. In the technology catch-up stage, the market and technical route are determined, and the effect of government plan and project guidance policy is obvious. In the frontier technology field and breakthrough innovation stage, it is difficult to rely on the planned projects to promote innovation without lesson from the past. The government mainly supports the preliminary $\mathrm{R} \& \mathrm{D}$ and demonstration projects, and the industrial technology route and development direction are selected by the market. Second, according to different fields, we should carry out classified guidance. In some key strategic areas of national security and important public areas related to people's livelihood, the government can support innovation by means of major science and technology projects, introduction of technology, digestion, absorption and localization. In the face of the enterprise innovation facing the market demand, we should give full play to the role of market mechanism in the allocation of resources, and the government should adopt universal policies to guide and support.

\subsection{Establish a service innovation mechanism dominated by science and technology service enterprises, and promote the science and technology service system to become an effective carrier of scientific and technological innovation and technological entrepreneurship}

At present, the phenomenon of "two skins" in science and technology and industry is still very prominent, which also exposes the problems such as the relative independence of research and development institutions and industrial system, and the lack of research and development strength and motivation of market players. A technology generally needs to go through two stages from research and development to technology transfer and product marketing: the first stage is research and development, including basic research, application research and technology development, the second stage is transformation, including design, production, sales and after-sales service. There are obvious differences between the two stages, and their implementation conditions and implementa-tion methods are also different. In the development phase, you only need to have an idea, implement the idea and prove its correctness, or make samples according to the idea. In the transformation stage, it is necessary to put the samples into production practice, turn the samples into products, sell them to the market and obtain economic and social values. The research and development stage is mainly carried out in the laboratory, while the transformation stage needs to be carried out in the factory. In the development phase, a small number of people are meticulous, while in the transformation stage, large-scale production technology and equipment are used for mass production, and the products are sold to the market.

Because the above two stages are significantly different, they are easily disjointed, leading to the break of innovation chain. The worst result is that universities and research institutes engaged in basic research do not know what technologies are needed by enterprises and their research content is not grounded in reality. Enterprises with low investment in innovative research do not get sufficient technical support and end up with "copycat" and "imitation". This is a fairly common problem, almost all 
over the world. To solve this problem, it is necessary to give full play to the role of the government and the market, start from the practical needs, and make use of the government-industry-university-research-application multi-party collaborative platform to promote the unification of basic scientific research and technology industrialization on the law of technology development.To be specific, the basic research related to the $r \& d$ stage mainly depends on the government investment, and the willingness of enterprises to invest in basic research is not demanding. The industrialization inseparable with the transformation stage needs to make micro-innovation and re-innovation constantly, which mainly depends on the investment of enterprises. Of these two aspects, the former relies on the government to lead, the latter relies on the initiative of the enterprise, the effective linkage between the two ends needs the mechanism to drive.

\section{$2.3 \mathrm{We}$ will improve the mechanism for collaborative innovation by integrating industry, education and research, and strengthen effective links between scientific and technological services in the innovation chain and industrial chain}

Collaborative innovation between enterprises, universities and research institutes is based on sharing innovative resources and complementing each other's advantages. Under the principle of cooperative R\&D, benefit sharing and risk sharing, the group will form a community of interests over a period of time, and jointly carry out scientific and technological innovation and promote the transformation of achievements. Domestic and foreign enterprises, universities and research institutes have gradually evolved from the initial special cooperation to the recent collaborative innovation and deep integration, which can be summarized as follows: government policy guidance and platform building, industry enterprises lead multi-party cooperation, universities as the base to attract enterprise cooperation, all parties join hands to build regional clusters. On the whole, there is a spectrum of industry-university-research collaborative innovation from shallow to deep: all parties reach a general resourcesharing agreement. To realize the cooperation of a single project or several projects, carry out cross-agency and multi-project cooperation, establish network alliance and establish strategic alliance, the establishment of strategic alliance will reach the highest level of deep integration. At present, there are basically two driving forces in the world. One is that external demand is driven by government regulation; the other is that all parties involved are mainly driven by contracts of internal interests. Among them, the coordination of interests between the enterprises, universities and research institutes is very important, and the boundaries of rights, responsibilities and interests should be confirmed according to regulations, and the risk sharing and benefit distribution mechanism should be set up.

\subsection{Starting from the institutional arrangement to realize the breakthrough development of science and technology finance, to meet the demand of science and technology service innovation}

To promote the breakthrough of science, technology and finance in China, we must innovate from the institutional level. Scientific and technological innovation is the first driving force of industrial upgrading and economic development, while finance is the core of modern economy, the hub of social resource allocation and an important lever to promote scientific and technological innovation. Scientific and technological innovation needs the help of finance and must be combined with financial innovation. Science and technology finance is the integration of science and technology and finance, as well as the systematic and innovative arrangement of a series of financial instruments, financial systems, financial policies and financial services to promote the development of science and technology, achievement transformation and high-tech industry. Innovation is the essential attribute of science and technology finance, the inexhaustible driving force for the development of science and technology finance, and the basic path for the development of science and technology finance. At present, there are many new models of science and technology finance in China. Under the background of "Internet Plus", structural and complex financial products have emerged. As well as angel investment, industrial investment, government venture investment and other new technology and financial products continue to emerge, it is of great practical significance to study the innovative approaches of China's technology and financial under the new normal of the economy.

\subsection{We will attach great importance to the development of all kinds of scientific and technological innovation service personnel, and establish a sound service chain for such personnel}

The three most important sub-elements of innovation environment are manpower, capital and service.Talent is the core driving force for the development of scientific and technological innovation, and attracting, retaining and using good people is the important work to promote scientific and technological innovation.It is one of the supporting points for the agglomeration and development of the modern science and technology service industry that the high-end science and technology service industry talents master the operation knowledge of the modern science and technology service industry.In the future, the development of science and technology service industry should focus on high-end management and professional talents. First, we will create a favorable environment for overseas returnees and senior experts with experience in international science and technology services by providing various preferential policies. Second, effective training measures should be established to provide training courses for senior professionals in science, technology and service industries, so as to train a group of international talents who are proficient in international 
practices and familiar with international rules of science, technology and service industries. Third, strengthen the training of high-end talents in science and technology service industry and strengthen the exchange and interaction of talents.

\section{Conclusion}

The influence mechanism of science and technology service industry to promote economic growth is not only the direct contribution to economic growth, but also the indirect contribution through the circuitous effect of influencing factors on economic growth. Summarize the above research content, we can draw the following conclusions:

- Establish a market-oriented mechanism for science and technology services and improve the allocation and utilization efficiency of science and technology resources.

- Establish a service innovation mechanism dominated by science and technology service enterprises, and promote the science and technology service system to become an effective carrier of scientific and technological innovation and technological entrepreneurship.

- We will improve the mechanism for collaborative innovation by integrating industry, education and research, and strengthen effective links between scientific and technological services in the innovation chain and industrial chain.

- $\quad$ Starting from the institutional arrangement to realize the breakthrough development of science and technology finance, to meet the demand of science and technology service innovation.

- We will attach great importance to the development of all kinds of scientific and technological innovation service personnel, and establish a sound service chain for such personnel.

On the basis of the above conclusions, we should take safeguards for the implementation of the system of innovation in scientific and technological services.

\subsection{Strengthen Organizational Leadership}

Improve the work coordination mechanism led by the leaders in charge, with the participation of relevant departments and district governments. Relevant departments should strengthen communication and close cooperation to form synergy and jointly promote the development and growth of the science and technology service industry. Governments at all levels should, in light of the positioning of regional development and the characteristics of industries, refine policies and measures, improve working mechanisms, and provide supporting support for land and human resources in order to create a favorable environment for the development of science and technology services.

\subsection{Monitoring Analysis}

We will improve the system of statistics and monitoring indicators for science and technology services, and strengthen statistics and monitoring of science and technology services. According to the statistical classification standards of the national science and technology service industry, the research on measurement methods should be carried out to accurately grasp the development status of the industry. We will strengthen cooperation with think tanks and conduct research and analysis on new technologies, new models and new trends in the development of science and technology services.

\section{Acknowledgment}

Supported by Jilin Province Social Science Fund Project (2018BS36): Research on the brand development strategy of agricultural products driven by financial service innovation in Jilin Province.

Supported by Scientific Research Planning Project of Jilin Provincial Education Department (JJKH20200166SZ): Research on the construction of accounting major from the perspective of curriculum ideological and political.

\section{References}

1. X. kui-xi, X. Yue-yue, X. Shi-chang. Institutional arrangement and policy Suggestions for achieving breakthrough development of science and technology finance in the innovation-driven background -- based on the reference of system innovation of science and technology finance in developed countries and regions $[\mathrm{J}]$. Science and technology progress and countermeasures,2016,33(23):105-110.

2. S. Jing. Research on the Status quo of Rural Science and Technology Services under the Background of Internet -- A Case study of Tinghu District, Yancheng City [J]. Modern Agricultural Science and Technology,2019(05):233-234+236.

3. L. Fei, Qiao Han. Evolution of industrial product service business model driven by digital technology - a case study of goldwind technology [J]. Management review,2019,31(08):295-304.

4. S. Chuanlin, Wang Liping. Research on the Development Path of Science and Finance from the innovation-Driven Perspective [J].2016 (11) : 65-69.

5. M. Liyi, Yang Yi. Research on growth Mechanism of High-tech Enterprises Based on Science and Technology Financial Network [J]. Scientific Research Management, 2013 (34) :339-342.

6. L. Wenyan, W. Shusheng. Financial development and industrial structure upgrading: An Empirical Study Based on the perspective of economic crisis [J]. Financial forum, 2016,21 (03): 18-29.

7. L. Yifu. Industrial policy and China's economic development: the perspective of new structural economics [J]. Fudan Journal (SOCIAL SCIENCE EDITION), 2017,59 (02): 148-153.

8. W. Zhenxin, X. Xiaojing, W. Shuping. Analysis of the impact of economic growth and industrial 
structure on carbon emissions -- Based on China's Provincial Panel Data [J]. China management science, 2012,20 (03): 161-166.

9. X. Haiqing. Empirical test of economic growth, industrial development and employment structure in China [J]. Economic issues, 2012 (01): 13-16. 